\title{
An analysis of mathematics understanding of prospective student-teachers of mathematics
}

\author{
Ali Mahmudi \\ Department of Mathematics Education, Universitas Negeri Yogyakarta \\ Jl. Colombo No. 1, Karangmalang, Yogyakarta 55281, Indonesia \\ E-mail: alimahmudi@uny.ac.id
}

\begin{tabular}{|c|c|}
\hline ARTICLE INFO & ABSTRACT \\
\hline $\begin{array}{l}\text { Article history } \\
\text { Received: } 17 \text { Oct } 2021 \\
\text { Revised: } 26 \text { Nov } 2021 \\
\text { Accepted: } 29 \text { Nov } 2021\end{array}$ & $\begin{array}{l}\text { This quantitative-qualitative descriptive study aims to reveal the mathematics } \\
\text { understanding of prospective student-teachers, describe the types of their } \\
\text { mistakes in mathematics understanding, and recommend appropriate teaching of } \\
\text { mathematics understanding. The subjects were } 34 \text { first-year students taking the } \\
\text { Geometry course in the Mathematics Education Study Program, at a State }\end{array}$ \\
\hline $\begin{array}{l}\text { Keywords } \\
\text { mathematical } \\
\text { representation, procedural } \\
\text { instrumental } \\
\text { understanding, prospective } \\
\text { mathematics teacher, } \\
\text { relational understanding. }\end{array}$ & $\begin{array}{l}\text { University in Yogyakarta, Indonesia. The test instrument was consisting of four } \\
\text { items, two of which were about the problems of procedural instrumental } \\
\text { understanding and the other two were about the problems of relational } \\
\text { understanding. The data were analyzed through the stages of reducing data, } \\
\text { presenting data, and concluding data. The results show that students' } \\
\text { mathematical understanding is categorized as good }(87.75 \%) \text {. Students' } \\
\text { procedural instrumental understanding }(87.75 \%) \text { is better than their relational } \\
\text { understanding }(77.52 \%) \text { which is in good and sufficient categories, respectively. }\end{array}$ \\
\hline $\begin{array}{l}\text { Scan me: } \\
\text { 口) }\end{array}$ & $\begin{array}{l}\text { Some students made mistakes in representing theorems, performing } \\
\text { mathematical procedural using appropriate concepts/theorems, and interpreting } \\
\text { conclusions or proofs using appropriate notation and representation. It is } \\
\text { recommended that mathematical learning should prioritize relational } \\
\text { understanding by exploring a concept with other concepts and using various } \\
\text { representations, situations, and contexts. Learning should focus more on } \\
\text { relational understanding, namely discussing a concept and its relationship with } \\
\text { other concepts with different representations, situations, and contexts. }\end{array}$ \\
\hline
\end{tabular}

This is an open access article under the CC-BY-SA license.

How to Cite: Mahmudi, A. (2021). An analysis of mathematics understanding of prospective student-teachers of mathematics. Jurnal Riset Pendidikan Matematika, 8(2), 167-178. https://doi.org/10.21831/jrpm.v8i2.44422

\section{INTRODUCTION}

Mathematical understanding is the main goal of teaching and learning mathematics (NCTM, 1989; Kemdikbdud, 2016). According to the National Council of Teachers of Mathemaics [NCTM], teachers should help students to develop conceptual and procedural understanding in every aspect of mathematics (NCTM, 1991, 21). Mathematics teaching and learning in Indonesia is intended to achieve mathematical understanding, including factual understanding, conceptual and procedural knowledge (Kemdikbud, 2016).

Mathematical understanding has become an important theme in mathematics education research. Many recent scientific articles on mathematics education make mathematical understanding the main theme. However, most of the research studies have concentrated on teaching and learning mathematics in primary and secondary schools. Research on mathematical understanding at university is still rare (Li \& Yang, 2019), especially for prospective mathematics teacher students.

Mathematics at university has characteristics relatively different from mathematics in schools related to depth and details. Mathematics at the university has a more significant role to develop systematic thinking skills. This role requires a higher level of understanding. Therefore, research on mathematical understanding at university is very relevant, especially for prospective mathematics 
teachers students. A good mathematical understanding from prospective teachers is a requirement to become a professional mathematics teacher. What is mathematical understanding? According to Romberg (Hoosain, 2001), there was no single definition of mathematical understanding. There are a different perception of mathematical understanding, from the simple one recalling a fact or definition of a mathematical concept to formulate and prove a statement or theorem.

Skemp (1978) classifies mathematical understanding into instrumental and relational understanding. Instrumental understanding is a low level understanding called 'rules without reasons'. Students with this understanding can apply a formula or mathematical procedure well, but cannot explain why the formula or procedure is appropriate. While relational understanding is a higher level of understanding called "knowing what to do and why". This understanding is not only characterized by the ability to use mathematical formulas or procedures correctly. However, they can also explain it. For example, students with this understanding are not only able to construct a circumcircle, but also are able to explain the underlying mathematical concepts, namely the triangle congruence theorem.

Zhao, Zezhong \& Sun (2015) state that mathematical understanding is related to cognitive processes, namely the formation of conceptual understanding as a process of assimilation and adaptation of new concepts to the structure of concepts that have been formed. This is in line with the meaning of relational understanding from Skemp (1978). Student's level of understanding of mathematics was indicated by the abilty level to integrate and explain related mathematical concepts.

Davis (Hoosain, 2001) classifies mathematical understanding as procedural and conceptual understanding. Procedural understanding includes some aspects, namely applying mathematical procedures holistically so that the correct answer is obtained and knowing the prior knowledge for implementing the procedure and knowing why and when the procedure is appropriate. While conceptual understanding includes the ability to detect errors when applying a procedure, provide logical arguments in applying a procedure, and recognize new types of mathematical problems when applying the procedure. These two categories of mathematical understanding are identical to the categories of mathematical understanding according to Skemp (1978).

NCTM (1989) describes mathematical understanding not only related to the ability to recall definitions or to recognize and give examples of a concept, but also to be able to recognize the relationship between concepts, represent a concept in various ways, recognize the relationship between representations of a concept and transform a concept into a different representation. This is in line with the definition of mathematical understanding according to Cramer \& Karnowski (1995), which refers to the ability to represent mathematical ideas in various ways and make connections between these different representations. Students with this understanding can recognize that ${ }^{a} \log b=c$ is equivalent to $a=b^{\mathrm{c}}$ and recognize that $2 x+3 y=5$ is equivalent to $y=-\frac{2}{3} x+5$. Students can also represent a problem in an appropriate visual representation regarding the congruence of two triangles.

NCTM (1989) provides a further definition of mathematical understanding as the ability to communicate mathematical concepts or ideas orally or in writing and to be able to apply mathematical concepts in problem solving. For example, students can solve problems related to the concept of congruence with the appropriate postulates and write down the process of solving the problem in a coherent, systematic and communicative way.

Mathematical understanding is constructed in the mind, so it is not easy to recognize and measure. Measurement of mathematical understanding has become a major issue (Skemp, 1976). Since the process of understanding takes place in the mind, it is not easy to do so. Maybe we will only measure a part of it. Hoosain (2001) describes some indicators of mathematical understanding. The first is to recognize mathematical structures in various situations or representations, for example recognizing that $2 x+3 y=5$ has the same form or structure as $2\left(\frac{1}{p}\right)+3\left(\frac{h}{7}\right)=5$. The second is to monitor and control the thinking process so that it can recognize an incorrect representation or procedure and can initiate correct steps, for example recognizing that even though it fulfills the side - side - angle postulate, two triangles are not congruent if they are different types.

The third indicator of mathematical understanding according to Hoosain (2001) is recognizing whether the final answer to a problem makes sense. For example, in solving a mathematical problem to determine the length of the third side of a triangle that is known to be the length of the other two sides, for example $3 \mathrm{~cm}$ and $4 \mathrm{~cm}$, students will recognize that an answer of more than $7 \mathrm{~cm}$ for the length of 


\section{Jurnal Riset Pendidikan Matematika, 8 (2), 2021 - 169}

Ali Mahmudi

the third side is an illogical answer because it contradicts other properties, namely that the length of the third side of a triangle is not more than the sum of the lengths of the other two sides.

By referring to various definitions and classifications, mathematical understanding can be defined as the ability to represent mathematical concepts or ideas using appropriate mathematical representations and carry out mathematical procedures coherently and communicatively in the process of solving problems or proving mathematical properties. Mathematical understanding can be classified into instrumental procedural and relational understanding. Both types of understanding need to be developed, but mathematics teaching and learning needs to focus more on developing relational understanding. Relational understanding focuses on the relationship between mathematical concepts which by Skemp (1976) calls a schematic understanding. Such learning has implications for better memorization of mathematical concepts.

Students' mathematical understanding was still not good (Sahin, Yenmez, \& Erbas, 2014). For example, students do not yet recognize the "big ideas" that underlie derivative concepts. Even though students can solve derivative tasks or problems correctly, which implies procedural instrumental understanding, they do not really understand the concept of derivation conceptually. Furthermore, Bardini et al (2014, p.1) also show that many students with high entry scores to university also have a very limited understanding of the function concept, even though they learn this concept in high school. Meanwhile, most of the students are not able to explain the appropriate function definition and are unable to recognize the correct relationship between graphs and tables of function. This fact shows that there is still a low level of relational understanding shown by the ability to relate mathematical concepts. This is in line with the study of Donevska-Todorova (2016) which also shows that students have problems understanding the concept of Linear Algebra. They do not understand the appropriate meaning of linearity.

A low understanding of relational mathematics is also shown by the study of Ayvaz, Gündüz \& Bozkuş (2017, p.1). Prospective mathematics teacher students have difficulty understanding the relationship between quadrilaterals, such as parallelogram, rhombuse and kite. They also have difficulty in proving the properties of quadrilaterals. The study of Baktemur, Ayan Civak, \& Isiksal Bostan (2021) shows that prospective mathematics teacher students have misunderstandings in classifying hierarchical quadrilaterals, multiple-inclusion relationships (eg, rhombus-trapezoid) and difficulties in formulating the definition of a quadrilateral by relating it to other quadrilaterals.

The lack of relational understanding of prospective mathematics teacher students is certainly a serious problem because it have an impact on their performance in carrying out professional duties as mathematics teachers in secondary schools. It can also have an impact on the students' mathematical relational understanding in secondary schools. Several studies have shown that students' mathematical understanding in secondary schools is low. The study of Borji, Alamolhodaei, \& Sánchez (2018) show that most students have big problems in developing mental constructions and doing the practical work needed to solve problems, especially regarding mental constructions that must be made to calculate derivatives at critical points, to determine velocity and understand variations in the slope of the tangent line. Another study by Unlüer \& Kurtulus (2021) show that students are not able to fully achieve a procedural and conceptual understanding of the identity $(a-b)^{2}$ and a procedural understanding of the identity $a^{2}-b^{2}$.

This study, therefore, aims to describe the mathematical understanding of prospective mathematics teacher students which includes instrumental procedural understanding and relational understanding. This study also aims to identify student errors in solving mathematical understanding problems and provide teaching and learning suggestions that can further improve mathematical understanding. The fact that students' mathematical understanding is still low, especially relational understanding, makes efforts to develop it a priority.

\section{METHOD}

This quantitative-qualitative descriptive research is intended to describe mathematical understanding, identify errors in solving mathematical understanding problems, and provide teaching and learning suggestions to improve mathematical understanding. The subjects were 39 first-year of prospective mathematics teacher of the Mathematics Education Study Program, at a State University in Yogyakarta, Indonesia. The research was conducted in September 2020 in the Geometry course. 
The instrument of this research is a test of mathematical understanding which consists of 4 problems. The first and second problems are related to procedural instrumental understanding to measure the ability to construct the circumcircle and the incircle of a triangle. The third and fourth problems measure relational understanding in providing a rational explanation of the mathematical procedure. This relational understanding involves various related mathematical concepts, namely circle, perpendicular bisector, angle bisector and triangle congruence. This instrument has been reviewed by experts to ensure its validity. Table 1 and Table 2 describe rubric scoring for procedural instrumental and relational understanding.

Data were analyzed quantitatively and qualitatively. Quantitative techniques to describe and analyze categories of mathematical understanding and qualitative techniques to analyze the types of student errors in solving mathematical understanding problems and to formulate learning suggestions to improve mathematical understanding. The first step of data analysis is data reduction, namely classifying and simplifying data according to indicators of mathematical understanding and identifying types of errors in solving mathematical understanding problems. The second step is data presentation, which is presenting data on mathematical understanding in tables according to the indicators and presenting data on the types of student errors in solving mathematical understanding problems. The third step is making conclusions regarding mathematical understanding, types of errors in solving mathematics understanding problems, and providing teaching and learning suggestions that can further improve mathematical understanding. Categories of mathematical understanding are presented in Table 3.

Table 1. Rubric scoring for procedural instrumental understanding

\begin{tabular}{cl}
\hline Score & \multicolumn{1}{c}{ Descriptions } \\
\hline 3 & $\begin{array}{l}\text { Construct the circumcircle or incircle of a triangle accurately and write down correct, } \\
\text { complete, and coherent construction procedures }\end{array}$ \\
2 & $\begin{array}{l}\text { Construct the circumcircle or incircle of a triangle accurately and write down the construction } \\
\text { procedure, but it's incomplete or incoherent }\end{array}$ \\
1 & $\begin{array}{l}\text { Construct the circumcircle or the incircle of a triangle accurately, but do not write down the } \\
\text { construction procedure. }\end{array}$ \\
\hline
\end{tabular}

Table 2. Rubric scoring for relational understanding

\begin{tabular}{|c|c|c|}
\hline No & Aspect & Score and descriptions \\
\hline 1 & $\begin{array}{l}\text { Represents statement or } \\
\text { theorem }\end{array}$ & $\begin{array}{l}\text { Score } 2 \\
\text { Sketch the circumcircle or incircle as a representation of the } \\
\text { theorem or statement and identify congruent triangles using } \\
\text { appropriate notation and provide a coherent and complete } \\
\text { description } \\
\text { Score } 1 \\
\text { Construct a sketch representation of a statement or theorem using } \\
\text { appropriate notation, but unable to identify congruent triangles }\end{array}$ \\
\hline 2 & $\begin{array}{l}\text { Carry out mathematical } \\
\text { proof procedures }\end{array}$ & $\begin{array}{l}\text { Score } 3 \\
\text { Carry out a complete and systematic mathematical proof procedure } \\
\text { using congruence properties so that the correct answer or } \\
\text { mathematical proof is obtained } \\
\text { Score } 2 \\
\text { Carry out mathematical proof procedures using congruence } \\
\text { properties, but not systematically } \\
\text { Score } 1 \\
\text { Carry out incomplete mathematical procedures or use inappropriate } \\
\text { congruence properties and do not obtain appropriate proofs }\end{array}$ \\
\hline 3 & $\begin{array}{l}\text { Conclude and interpret } \\
\text { proof }\end{array}$ & $\begin{array}{l}\text { Score } 2 \\
\text { Provide conclusion and appropriate interpretation } \\
\text { Scor } 1 \\
\text { Provide inappropriate conclusion and interpretation }\end{array}$ \\
\hline
\end{tabular}


Table 3. Mathematical understanding category

\begin{tabular}{ll}
\hline Mathematical understanding score $(x)$ & Category \\
\hline $90 \leq x \leq 100$ & Very good \\
$80 \leq x \leq 90$ & Good \\
$70 \leq x \leq 80$ & Pretty good \\
$x<70$ & Not good \\
\hline
\end{tabular}

\section{RESULT AND DISCUSSION}

Data were obtained from four problems of mathematical understanding which consisted of two problems of procedural instrumental understanding and two problems of relational understanding. Table 4 shows that the average mathematical understanding of students is $2.01(80.59 \%)$ in good category. Based on the criteria in Table 3, there are 18 students (52.94\%) in the category of very good, five students $(14.71 \%)$ in the good category, five students $(14.71 \%)$ in the pretty good category and six students $(17.65 \%)$ with not good category.

Table 4. Data of mathematical understanding

\begin{tabular}{|c|c|c|c|c|c|c|c|c|}
\hline & \multicolumn{2}{|c|}{$\begin{array}{c}\text { Prosedural instrumental } \\
\text { understanding }\end{array}$} & \multicolumn{6}{|c|}{ Relational understanding } \\
\hline & \multirow{2}{*}{ Problem 1} & \multirow{2}{*}{ Problem 2} & \multicolumn{3}{|c|}{ Problem 3} & \multicolumn{3}{|c|}{ Problem 4} \\
\hline & & & $\mathrm{A}$ & B & $\mathrm{C}$ & $\mathrm{A}$ & $\mathrm{B}$ & $\mathrm{C}$ \\
\hline Minimum & 1 & 1 & 0 & 0 & 0 & 0 & 0 & 0 \\
\hline Maximum & 3 & 3 & 2 & 3 & 2 & 3 & 3 & 2 \\
\hline Ideal score & 3 & 3 & 2 & 3 & 2 & 2 & 3 & 2 \\
\hline $\begin{array}{l}\text { Standard } \\
\text { deviation }\end{array}$ & 0.58 & 0.69 & 0.55 & 0.81 & 0.68 & 0.59 & 0.88 & 0.72 \\
\hline \multirow[t]{2}{*}{$\begin{array}{l}\text { Average of } \\
\text { each indicator }\end{array}$} & $\begin{array}{c}2.68 \\
(89.22 \%)\end{array}$ & $\begin{array}{c}2.59 \\
(86.27 \%)\end{array}$ & $\begin{array}{c}1.59 \\
(79.41 \%)\end{array}$ & $\begin{array}{c}2.53 \\
(84.31 \%)\end{array}$ & $\begin{array}{c}1.35 \\
(67.65 \%)\end{array}$ & $\begin{array}{c}1.62 \\
(80.88 \%)\end{array}$ & $\begin{array}{c}2.41 \\
(80.39 \%)\end{array}$ & $\begin{array}{c}1.35 \\
(67.65 \%)\end{array}$ \\
\hline & & & \multicolumn{3}{|c|}{$1.82(78.15 \%)$} & \multicolumn{3}{|c|}{$1.79(76.89 \%)$} \\
\hline
\end{tabular}

Average of

each type of

understanding

Total

$2.01(80.59 \%)$

average

Note: aspects of relational understanding skills: A (represent statements or theorems, B (carry out mathematical proof procedures), and C (conclude and interprete proofs).

The average of students' procedural instrumental understanding is $2.63(87.75 \%)$ which is in a good category. Generally, students can construct the circumcircle and the incircle of a triangle and write down procedures well. There are only 2 and 3 students who construct the circumcircle and the incircle of a triangle incorrectly. The student's ability to construct the circumcircle of a triangle is better than the ability to construct the incircle, with an average of 2.68 (89.22\%) and $2.59(86.27 \%)$, respectively.

The procedure for constructing the circumcircle of a triangle is simple, so that students' ability to do it is better than constructing the incircle. The procedure for constructing the circumcircle of a triangle is to construct scalene triangle, construct the three perpendicular bisectors of the sides and construct the circumcircle of the triangle with the center of the intersection of the three perpendicular bisectors and the radius of the distance from the point of intersection to one of the vertices of the triangle. While the procedure for constructing the incircle of a triangle is to construct scalene triangle, construct the three angle bisectors and construct the incircle of the triangle with the center of the intersection of the three angle bisectors and the radius of the distance from the point of intersection to one of the sides of the triangle. 
Students' procedural instrumental understanding is much higher than relational understanding with an average of $2.68(87.75 \%)$ and $1.81(77.52 \%)$ with good and pretty good category, respectively. Indeed, procedural instrumental understanding is a lower and mechanistic understanding which Skemp (1978) characterizes as "rule without reason". This understanding is simpler than the relational understanding which Skemp (1978) characterized as "knowing what to do and why". Students with good procedural instrumental understanding, for example being able to use the procedure for constructing circumcircle and incircle well, do not necessarily have a good relational understanding, which is not necessarily able to explain why the procedure is correct by using relevant mathematical concepts or principles.

Table 5 provides an explanation that in general there is a very good relationship between students' procedural instrumental understanding and relational understanding. There are 17 (50\%) students who have good and very good procedural instrumental understanding with good and very good relational understanding. Likewise, there are $9(26.47 \%)$ students whose procedural instrumental understanding and relational understanding in a not good category. However, there are $17.65 \%$ of students with very good instrumental understanding, but lack of relational understanding. This fact shows that a good procedural instrumental understanding is not necessarily a prerequisite for a good relational understanding.

Table 5. The relationship between procedural instrumental and relational understanding

\begin{tabular}{lllll}
\hline \multirow{2}{*}{$\begin{array}{l}\text { Prosedural instrumental } \\
\text { understanding }\end{array}$} & Not good & Pretty good & Good & Very good \\
\cline { 2 - 5 } $\begin{array}{l}\text { Not good } \\
\text { Pretty good }\end{array}$ & $9(26.47 \%)$ & $1(2.94 \%)$ & $1(2.94 \%)$ & $4(11.75 \%)$ \\
Good & & & $1(2.94 \%)$ & \\
Very good & $6(17.65 \%)$ & $1(2.94 \%)$ & $10(29.41 \%)$ & $7(20.59 \%)$ \\
\hline
\end{tabular}

Relational understanding data obtained from problem 3 and problem 4 to measure students' ability to provide logical arguments against the procedures for constructing the circumcircle and the incircle of the triangle. Problem 3 measures the student's ability to prove that the intersection point of three perpendicular bisector of the sides is a center of circumcircle with the radius being the distance from the point to one of the vertices of the triangle. While problem 3 measures the student's ability to prove that the intersection point of three angle bisectors is a center of incircle with the radius being the distance from the point to one of the sides of the triangle. Table 6 presents mathematical relational understanding data according to the indicators.

Table 6. Data of relational understanding according to the indicators

\begin{tabular}{ll}
\hline Indicator of mathematical relational understanding & Score (percentage) \\
\hline Represents statement or theorem & $1.60(80.15 \%)$ \\
Carry out mathematical proof procedures & $2.47(82.35 \%)$ \\
Conclude and interpret proof & $1.94(67.65 \%)$ \\
\hline Average & $1.81(77.52 \%)$ \\
\hline
\end{tabular}

Table 6 presents that student have a good ability to represent statements or theorems using good sketches (average $80.15 \%$ ) and are also good at carrying out mathematical proof procedures using appropriate concepts (average $82.35 \%$ ). However, students' ability to conclude and interpret proof is still in the nearly good category. Figure 1 is an example of student work in solving problem 3. In general, this student's ability is good, which means being able to make complete and informative sketches to visually represent statements or theorems, can carry out appropriate mathematical procedures using the concept of congruent triangles, and can also conclude and interpret proof well. However, there are still some inaccuracies in using line segment and angle notation as well as incompleteness in providing a rational explanation of the proof steps by referring to the appropriate congruence postulate, namely the side-angle-side postulate. 


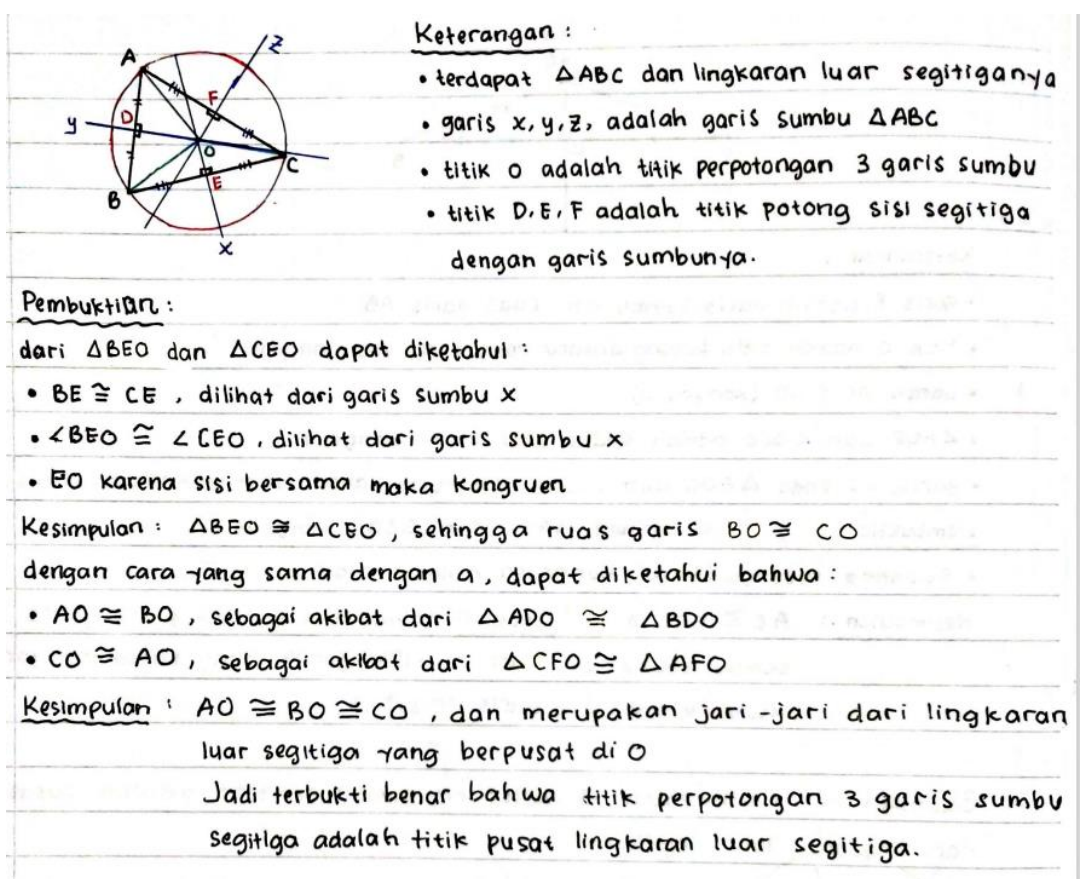

Figure 1. Examples of student work

There are $19.75 \%$ of students who are inapproriate in representing statements or theorems, for example shown by the results of student work in Figure 2. This student does not use scalene triangle as an illustration, but uses an isosceles triangle, so that the angle bisector and the perpendicular bisector coincide. He does not recognize the appropriate postulates or congruence theorems for proof so do not get the right appropriate conclusion or proof.

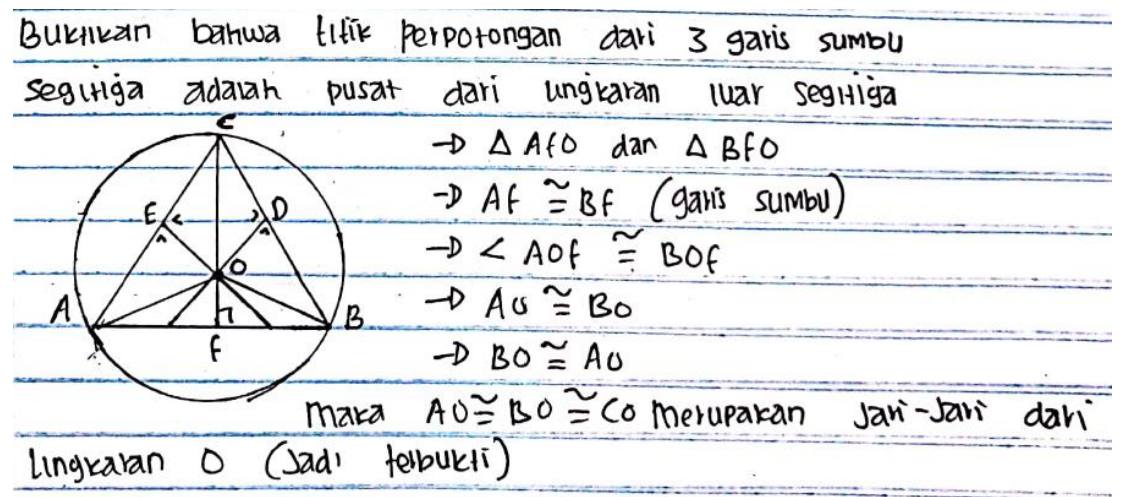

Figure 2. Examples of student work

The inaccuracy of student understanding is also shown by the results of student work in Figure 3. This student uses an inappropriate ilustration, namely isosceles or equilateral triangles, so that the angle bisector that should not have to be perpendicular to the sides of the triangle becomes perpendicular. The use of this inappropriate type of triangle has implications for the next error, namely the student cannot identify two congruent triangles, so that the correct evidence is not obtained. In addition, this student does not provide a coherent and communicative explanation for each step of proof by using relevant concepts or postulates.

The results of the analysis show that there are some types of student errors in solving proof problems, for example errors in representing statements or theorems using the right sketch. Students do not use scalene triangles, but use isosceles or equilateral triangles, so the conclusions cannot be generalized. With this special type of triangle, the special lines of the triangle coincide so that it is not easy to identify exactly which congruent triangles will be used in the proof. Students are also incorrect in using congruence concepts or postulates, for example the side-angle-side postulate. Whereas, 
representing the problem into an appropriate mathematical representation is an important first step in the process of proving and solving problems. The study of Gokalpa \& Bulut (2018) shows that there is a relationship between the use of appropriate conceptual representations and a good level of understanding of mathematical concepts. The study of Utomo (2020) also show that students with good academic abilities demonstrate the ability to write down important information from problems completely and accurately. On the other hand, students with low academic abilities are not able to fully translate propblems with appropriate representations.

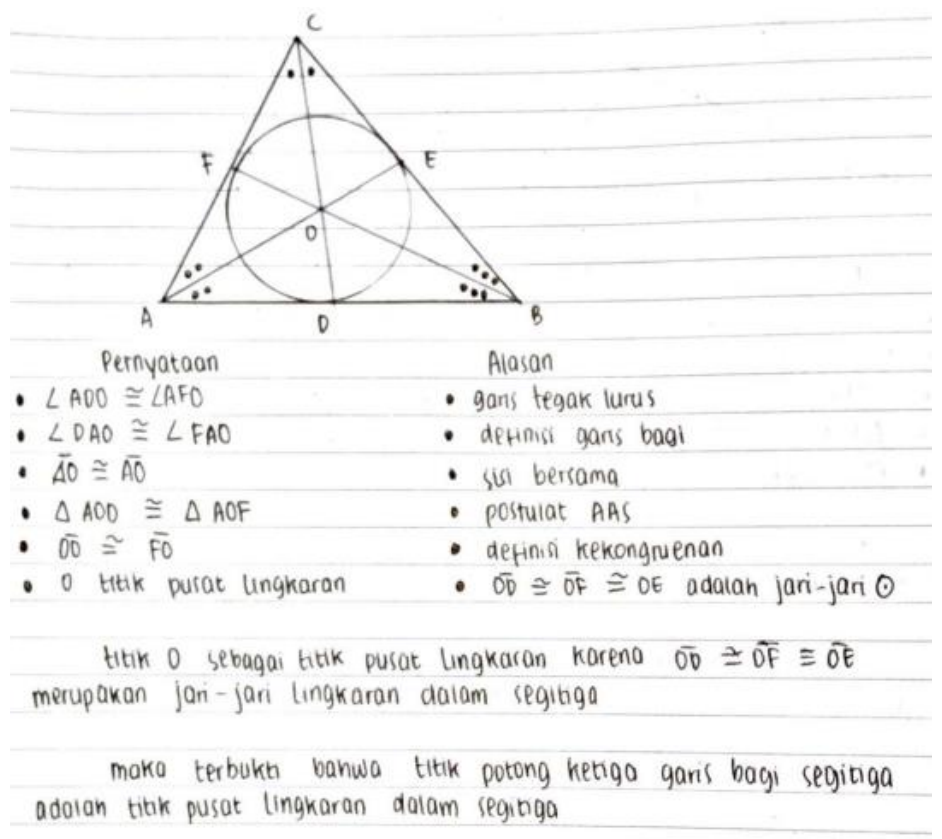

Figure 3. Examples of student work

Almost all students, although at different levels, do not provide appropriate arguments against each step of mathematical proof. This fact shows that students' mathematical communication skills still need to be developed, both orally and in writing. For prospective mathematics teacher students, this ability is very significantly needed and becomes an important provision for carrying out professional duties as teachers in the future. The study show that teacher communication skills have a very significant role in students' academic success, in addition to the use of appropriate strategies of teaching and learning (Khan, et al., 2017 \& Ibrahim, et al., 2019). Communication skills which are an important tool in social interaction are also one of the important competencies for teachers in Indonesia (Depdiknas, 2007).

The results of this study generally indicate that relational understanding is not good for prospective mathematics teacher students. This condition is in line with several previous studies (Sahin, Yenmez, \& Erbas, 2014; Ayvaz, Gündüz \& Bozkuş, 2017; \& Bactemur, Ayan Civak, \& Isiksal Bostan, 2021), namely even though students can perform mathematical procedures well, but they are unable to explain how the mathematical procedure is relevant and effective. For example, although students can solve differential problems, they can not recognize the role of big ideas about differential concepts. This implies that although students have a good instrumental understanding, they do not really understand what differential means conceptually.

Most students have a relational understanding that is still not good. Research by Bardini, et al. (2014, p. 1) shows that undergraduate mathematics students who have mastered mathematical procedural skills without conceptual understanding. Most students with good university entrance scores also have a limited understanding of the concept of function, even though this concept is present in the secondary school curriculum they have studied. While most students are not able to provide an appropriate function definition and are not able to recognize the correct relationship between graphs and function tables. 
There are several reasons why students' relational understanding is not good. Study of Engin \& Pusmaz (2021, p.11) shows that inadequate prerequisite knowledge causes students to achieve good mathematical reasoning and relational understanding. Inadequate mastery of prerequisite concepts has implications for students' inability to recognize connections between mathematical concepts. Poladian \& Zeng's (2016) study shows that students do not have a strong understanding of mathematical connections between areas of mathematics or the richness of connections between mathematics and other disciplines.

Mathematical understanding has a very important position in teaching and learning mathematics, so its development is a necessity. Based on the results of the analysis of students' procedural and relational instrumental understanding and paying attention to the types of errors made by students, there are several alternative suggestions for learning mathematics to further improve mathematical understanding. The study by Patkin \& Plaksin (2018) show that in order to achieve a good mathematical understanding, especially relational understanding, it is necessary to plan well and be integrated in the syllabus of mathematics teaching and learning.

Sierpinska (2000) provides recommendations for teaching and learning mathematics that support the achievement of a good mathematical understanding. He argues that learning mathematics should be viewed as a human activity that reflects the work of mathematicians, namely discovering why a mathematical technique or procedure is appropriate, discovering a new technique or proving a statement or theorem. Mathematics teaching and learning needs to avoid the concept transfer process by defining it directly, but by giving students access to explore the concepts they have learned to define new concepts. Furthermore, Sierpinska (2000) suggests that teaching and learning mathematics with understanding is characterized by the activity of students applying the knowledge they already know to learn new concepts and to solve new unfamiliar problems. Teaching and learning mathematics to achieve understanding is also characterized by student activities in building relationships, applying knowledge, reflecting on experience, articulating and formulating understanding, and internalizing mathematical concepts.

Teaching and learning mathematics should involve using relevant concepts that students already know and working on mathematical procedures in a meaningful way. Mathematical understanding can be constructed within a suitable semantic framework to describe and interpret its meaning. The research of Martín-Fernández \& Ruiz-Hidalgo (2019) shows that 88\% of students have expressed their understanding of the concepts of sine and cosine based on the idea of coherent meaning with a good semantic framework.

Mathematics teaching and learning needs to prioritize relational understanding over procedural instrumental learning. Understanding and being able to apply a procedure and formula is very important. However, understanding why and how the procedure and formula is correct is much more important. Teaching and learning a concept need to use multiple representations, introducing concepts to different situations and contexts. Mathematics teaching and learning also needs to explore the relationship between mathematical concepts, for example in teaching geometric constructions such as perpendicular lines, angle bisectors, circumcircles and incircles, it is necessary to explore the underlying mathematical concepts, especially the concept of congruence. This is in line with the study of Boaler et al (2016) that teaching and learning mathematics needs to explore mathematical concepts more visually. The study of Martín-Fernández \& Ruiz-Hidalgo (2019) show that 88\% of students have expressed their understanding of the concepts of sine and cosine based on the idea of coherent meaning with a good semantic framework.

Mathematics teaching and learning needs to explore the relationship between concepts to improve understanding of relational mathematics. The relationship between concepts can be in the form of a concept map. The study of Hammad, Dimitriadis and Graham (2021) shows that concept maps are effective as a tool to assess, monitor and improve students' mathematical understanding, especially their conceptual understanding when used systematically and followed up with discussions that encourage students to reflect and discuss their concept maps. A good mathematical understanding contributes to an increase in good mathematics learning achievement as well. It would be better, the concept map is not only compiled and discussed by the teacher, but can also be constructed and discussed by students. Constructing concept maps and providing detailed explanations is an important part of mathematical communication. Mathematics teaching and learning should facilitate students' activities to communicate 
and express their ideas in writing or orally. Communication skills and social interaction skills are very important to be mastered by prospective teacher because they are one of the main competencies of professional teachers in Indonesia (Depdiknas, 2007).

\section{CONCLUSION}

Students' mathematical understanding is categorized as good $(87.75 \%)$ with procedural instrumental understanding $(87.75 \%)$ which is better than relational understanding $(77.52 \%)$, in good and pretty good categories, respectively. Some types of student errors in solving mathematical understanding problems are errors in representing theorems, carrying out mathematical proof procedures using appropriate concepts or theorems, as well as interpreting and communicating conclusions or proofs using appropriate notation and representation. Mathematics teaching and learning should prioritize relational understanding by exploring concepts with other concepts and using various representations, situations, and contexts. Mathematics teaching and learning needs to facilitate the development of written and oral communication skills.

\section{REFERENCES}

Ayvaz, Ü., Gündüz, N., \& Bozkuş, F. (2017). Understanding of prospective mathematics teachers of the concept of diagonal. Journal on Mathematics Education, 8(2), 165-184. http://dx.doi.org/10.22342/jme.8.2.4102.165-184

Baktemur, G., Ayan Civak, R., \& Isiksal Bostan, M. (2021). Pre-service middle school mathematics teachers' (mis)conceptions of definitions, classifications and inclusion relations of quadrilaterals.

European Journal of Science and Mathematics Education, 9(4), 183-198. https://doi.org/10.30935/scimath/11206

Bardini, C., Pierce, R., Vincent, J., \& King, D. (2014). Undergraduate mathematics students' understanding of the concept function. IndoMS-JME, 5(2), 85-107. https://doi.org/10.22342/jme.5.2.1495.85-107

Boaler, J., Chen, L., Williams, C., \& Cordero, M. (2016). Seeing as understanding: the importance of visual mathematics for our brain and learning. Journal of Applied \& Computational Mathematics. 5(5), 1-6. https://www.hilarispublisher.com/open-access/seeing-as-understanding-theimportance-of-visual-mathematics-for-our-brain-and-learning-2168-9679-1000325.pdf

Borji, V., Font, V., Alamolhodaei, H., \& Sánchez, A. (2018). Application of the complementarities of two theories, APOS and OSA, for the analysis of the university students' understanding on the graph of the function and its derivative. EURASIA Journal of Mathematics, Science and Technology Education, 14(6), 2301-2315. https://doi.org/10.29333/ejmste/89514

Cramer, K., \& Karnowski, L. (1995). The importance of informal language in representing mathematical ideas. Teaching Children Mathematics, 1(6), 332-335. https://doi.org/10.5951/TCM.1.6.0332

Depdiknas. (2007). Permendiknas nomor 16 tahun 2007 tentang standar kualifikasi dan kompetensi guru [Permendiknas number 16 of 2007 concerning teacher qualification and competency standards]. Jakarta, Indonesia: Departemen Pendidikan Nasional RI.

Donevska-Todorova, A. (2016). Procedural and conceptual understanding in undergraduate linear algebra. Proceedings of the First Conference of International Network for Didactic (pp 1-12). Montpellier (France): University Mathematics. https://hal.archives-ouvertes.fr/hal01337932/document

Engin, Ö., \& Pusmaz, A. (2021). An analysis of high school students' understanding and reasoning of average concept. Turkish Journal of Computer and Mathematics Education, 12(1), 187-201. https://doi.org/10.16949/turkbilmat.780680

Gokalpa, N. D., \& Bulut, S. (2018). A new form of understanding maps: multiple representations with Pirie and Kieren Model of understanding. International Journal of Innovation in Science and Mathematics Education, 26(6), 1-21. https://core.ac.uk/download/pdf/229408574.pdf 
Hammad, S., Dimitriadis, C., \& Graham, T. (2021). Using concepts maps in a foundation mathematics course: what have we learnt?. EURASIA Journal of Mathematics, Science and Technology Education, 17(2), 1-17. https://doi.org/10.29333/ejmste/9700

Li, H., \& Yang, Z. (2019). Research on teaching strategies to realize mathematical understanding in university mathematics classes. Journal of Social Sciences and Humanities, 5(4), 428-431. http://files.aiscience.org/journal/article/pdf/70320331.pdf

Hoosain, E. (2001). What does it mean to understand mathematics? Humanistic Mathematics Network Journal, 8(1), 19-22. https://doi.org/10.5642/hmnj.200101.25.09

Ibrahim, M. Y., Yusof, M. R., Yaakob, M. F. M., \& Othman, Z. (2019). Communication skills: Top priority of teaching competency. International Journal of Learning, Teaching and Educational Research, 18(8), 17-30. https://doi.org/10.26803/ijlter.18.8.2

Kemdikbud. (2016). Permendikbud nomor 24 tahun 2016 tentang standar kompetensi inti dan kompetensi dasar sekolah dasar dan menengah Kurikulum 2013 [Permendikbud number 24 of 2016 concerning core competency standards and basic competencies for elementary and secondary schools 2013 Curriculum]. Jakarta, Indoneisa: Kementrian Pendidikan dan Kebudayaan RI.

Khan, A., Khan, S., Zia-Ul-Islam, S., \& Khan, M. (2017). Communication skills of a teacher and its role in the development of the students' academic success. Journal of Education and Practice, 8(1), 18-21. https://eric.ed.gov/?id=EJ1131770

Martín-Fernández, E., \& Ruiz-Hidalgo, J. F. (2019). Meaning and understanding of school mathematical concepts by secondary students: the study of sine and cosine. EURASIA Journal of Mathematics, Science and Technology Education, 15(12), 1-18. https://doi.org/10.29333/ejmste/110490

NCTM. (1989). Curriculum and evaluation standards for school mathematics. Reston, VA: National Council of Teachers of Mathematics.

NCTM. (1991). Professional standards for teaching mathematics. Reston, VA: National Council of Teachers of Mathematics.

Patkin, D. \& Plaksin, O. (2018) Procedural and relational understanding of pre-service mathematics teachers regarding spatial perception of angles in pyramids. International Journal of Mathematical Education in Science and Technology, 50(1), 121-140. https://doi.org/10.1080/0020739X.2018.1480808

Poladian, L. \& Zheng, C. (2016). Context, connections and communication: using journal articles in undergraduate mathematics. International Journal of Innovation in Science and Mathematics Education. $24(5)$, 14-23. https://openjournals.library.sydney.edu.au/index.php/CAL/article/view/10873

Sahin, Z., Yenmez, A. A. \& Erbas, A. K. (2014). Relational understanding of the derivative concept through mathematical modeling: A case study. Eurasia Journal of Mathematics, Science \& Technology Education, 11(1), 177-188. https://doi.org/10.12973/eurasia.2015.1149a

Sierpinska, A. (2000). Mathematics classroom that promote understanding. https://www.emis.de/journals/ZDM/zdm002r2.pdf

Skemp, R. (1976). Relational understanding and instrumental understanding. Mathematics Teaching, 77(1), 20-26. http://math.coe.uga.edu/olive/EMAT3500f08/instrumental-relational.pdf

Skemp, R. (1978). Relational understanding and instrumental understanding. Arithmetic Teacher, 26(3), 9-15.

Utomo, D. P. (2020). The pattern of a relational understanding of fifth-grade students on integer operations. Journal of Research and Advances in Mathematics Education, 5(2), 119-129. https://files.eric.ed.gov/fulltext/EJ1267457.pdf. 
Ünlüer, Ġ., \& Kurtulus, A. (2021). The examination of conceptual and procedural understanding processes of eighth grade students in the subjects of identities and factoring. Turkish Journal of Computer and Mathematics Education, 13(1), 22-70. https://doi.org/10.16949/turkbilmat.698535

Zhao, K., Zezhong, Y. \& Sun, D. (2015). Research on mathematical understanding in Mainland China. International Conference on Management, Computer and Education Informatization (MCEI 2015). https://doi.org/10.2991/mcei-15.2015.39 